\title{
Role Differentiation as a Dimension in Community Diagnosis ${ }^{1}$
}

\author{
Saul Cooper ${ }^{2}$ \\ Washtenaw County Community Mental Health Center and the University of Michigan
}

Role differentiations represent one type of diagnostic data in designing community interventions. This paper focuses on four aspects of role differentiations: the ascribed role, the attributed role, the assumed role, and the actual role. The ascribed role speaks to the formal legalistic underpinnings of a social system; the attributed role speaks to the perceptions of a variety of constituencies; the assumed role reflects the values and attitudes of the personnel of a social system; and the actual role defines the observable behavior of the personnel. In an ideal social system one would expect an almost total convergence of the four roles. Since the ideal social system rarely exists, the dissonance and disequilibrium among the four role dimensions produces valuable diagnostic data in designing community intervention strategies.

Community psychology continues to be the fastest growing division of the American Psychological Association. While the challenges and tasks that confront this new field are becoming increasingly clear, definitional and domain issues continue to plague us. These issues must be grappled with if we are to become anything more than a haven for discontented clinicians.

A variety of theoretical frameworks have begun to emerge in community psychology, and training activities have developed in more than 40 colleges and universities around the country, yet we are woefully lacking a solid research base on which to build substantive knowledge. As with most new fields of endeavor, community psychology leans heavily (sometimes too heavily) on experientially

\footnotetext{
${ }^{1}$ This paper was originally presented as the Division 27 (Community Psychology) Presidential Address at the annual meeting of the American Psychological Association, Montreal, September 1973.

${ }^{2}$ Requests for reprints should be sent to Saul Cooper, Washtenaw County Community Mental Health Center, 2929 Psymouth Road, Ann Arbor, Michigan 48105.
} 
based activities. Hopefully, such experiences can and will lead to fruitful theoretical formulations that will serve as a framework for research-based substantive knowledge in community psychology.

As a practitioner in human services for over 20 years, I would like to share some personal observations of role differentiations as they relate to community and system diagnosis. The appropriateness and success probability of intervention increases as one elicits and understands diagnostic data. Several dimensions of community diagnostic data can be identified: (1) role differentiations, (2) communication patterns, (3) power distribution, (4) decision-making processes, and (5) agency structural patterns. This paper will focus on four aspects of the role differentiations of a social system: the ascribed role, the attributed role, the assumed role, and the actual role.

The ascribed role of an institution or a social system is formally defined in an explicit and usually recorded manner. It might exist in terms of a law or a statute, or be represented by a constitution and a set of bylaws. In any case, the ascribed role tends to define the sanction and purpose of the social system. The ascribed role of a department of social services, a mental health center, a police department, or a block club can be ascertained relatively easily; yet, all too frequently, the community psychologist does not avail himself of this information prior to designing an intervention plan. It must be noted parenthetically that most of the personnel of human service institutions have little awareness of the ascribed roles of their own institution. The intent here is not to define ascribed roles as simplistic, clear-cut, diagnostic data. Rather, the intent is to highlight the critical importance of the ascribed role in a beginning attempt at diagnostic differentiation.

Many consultation programs to human service agencies have aborted because of a basic conflict between the ascribed role of the consultant's institution and the consultee's institution. Lack of adequate role-diagnostic information at the ascribed level frequently leads to intervention designs which produce extensive work effort but minimal results (Hassol \& Cooper, 1970).

The second diagnostic dimension is the attributed role, that is, the role of a social system or institution as perceived by a variety of critical constituencies in the community. For example, a department of social service has a wide range of attributes that include as a constituency welfare recipients, marginal bluecollar taxpayers, and governmental officials responsibie for welfare funding and programming. In one sense the range of critical role attributions reflects the field of forces that the community psychologist must recognize and take into account in designing his intervention model. Not only must one not overlook a significant constituency, but it is even more important that one recognize the nature and substantive content of the role attribution of the significant constituencies if the intervention is to succeed. Diagnostic data that overlook any given constituency or that do not fully identify the role attributions of interacting constituencies will frequently lead to intervention designs that polarize subsystems within a 
community and ultimately will lead to a more pathological state of affairs than actually existed before the community psychologist intervened.

The third role dimension, the assumed role, has to do with the deliverers of service. The personnel of the social system or institution operate from an attitudinal and value base which determines how they think they should be functioning or how they would like to function in their particular social system. For example one need only point out how some social workers in welfare departments define their assumed role, in contrast to how policemen who work in an inner-city ghetto define theirs. Data on the assumed role of personnel in any system represents a critical type of diagnostic information not easily accessible to the community psychologist. Valid assumed-role information depends on reasonably long-term contacts with a particular institution, but only becomes available if these long-term contacts produce a level of confidence and trust which opens up the assumed-role data. This third role dimension may represent the last bastion diagnostically, and yet it probably is the single most vital contributor to successful intervention outcomes.

The final role dimension is the actual role. This is most easily described as the behavior of the social system or institutional personnel as they carry out their assigned activities. These data are generally visible and observable. However, once again the degree of visibility will depend on the community psychologist's access to the institutional or social system. For example, the behavior of police officers on the midnight shift might provide critical diagnostic information, but such data are not generally available to the community psychologists.

In summary, we have defined four role differentiations which can be used diagnostically: the ascribed role, which speaks to the formal legalistic underpinnings of a social system; the attributed role, which speaks to the perceptions of a variety of constituencies who are either users, supporters, or providers of services; the assumed role, which reflects the values and attitudes of the personnel; and finally the actual role, which is the behavior carried out by the personnel.

In an ideal social system or institution, we would expect, theoretically, almost total convergence of the ascribed, attributed, assumed, and actual roles. In other words, there would be a high level of consonance between what the social system was meant to do, what a variety of constituencies want it to do, what the personnel of the system think they should be doing or would like to be doing, and, finally, how they actually behave. Since, in the real world, one rarely finds an ideal social system with no dissonance, we must expect and look for disequilibrium among the four role dimensions to obtain valuable diagnostic data in designing intervention strategies (Nagles \& Cooper, 1970).

Let us now consider several examples as they relate to advocacy in the human services field. One frequently finds that novice community psychologists focus on the most visible level of any social system, namely, the actual role of 
the personnel. For example, client advocacy for welfare recipients certainly has merits, but we must be concerned about advocating where it is easiest rather than where it is most appropriate. Advocacy at the actual role level may or may not be appropriate, depending upon an adequate, four-level, role dimension diagnosis.

As another example, one might consider the history of birth control legislation prior to the Supreme Court ruling. In many states, concerted efforts were focused on the ascribed role, that is, attempts to produce legislative changes. A closer diagnostic assessment might have suggested as a more proper focus the attributed roles of several significant constituencies about whom legislators were extremely sensitive and without whose support no legislative changes could have occurred. Thus, an intervention model focusing at the attributed role level might have been more successful.

As the psychologist moves from the laboratory to the community, his predilection will most often be towards the actual behavior, which involves relatively less complexity and is more "get-at-able." Yet, if an intervention is designed to focus on the actual behavioral level of the personnel of a social system, then one's diagnostic data should indicate that the ascribed role in no way constrains the behavior of the personnel, that the assumed roles are in some state of dynamic balance and therefore do not unduly constrain the actual behaviors of the personnel, and, finally, that assumed roles fit reasonably comfortably with actual behaviors.

It seems clear that community diagnosis requires diagnostic data which by its very nature infers a fairly close and intense connection between the diagnostician and the particular social system. With regard to role differentiations, one cannot diagnose in the abstract or from a distance. Meaningful diagnostic data only come from systematic, intensive, and sometimes lengthy contacts which, by their very nature, can be precarious and highly unstable.

As community psychologists, we seem to reflect an action orientation as part of our value system. However, development of sound practices in community psychology will depend very heavily on careful diagnostic assessments which, more often than not, will require at least some action delay. One wonders whether the novice community psychologist will be able to delay action while carrying out the diagnostic process. Will he have enough skills to slow down the system demands? More critically, will he have enough skills to delay his own needs to be doing the "important stuff" that constitutes active intervention?

\section{REFERENCES}

Hassol, L., \& Cooper S. Techniques of mental health consultation in a preventive context. In Henry Grunebaum (Ed.), The practice of community mental health. Boston: Little, Brown \& Co., 1970. 
Nagler, S., \& Cooper, S. Influencing social change in community mental health. In Patrick E. Cook (Ed.), Community psychology and community mental health. San Francisco: Holden-Day, Inc., 1970. 